\title{
IMMEDIATE/EARLY RADIOLOGICAL FINDINGS FOLLOWING TRANSCRESTAL SINUS AUGMENTATION USING A MINIMALLY INVASIVE IMPLANT DEVICE
}

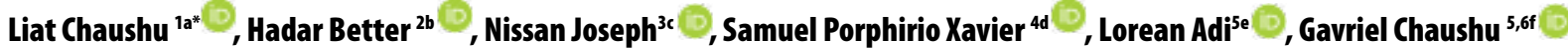 \\ 'Department of Periodontology and Implant Dentistry, The Maurice and Gabriela Goldschleger School of Dental Medicine, Tel Aviv University, Tel Aviv, Israel \\ 2Private practice, Tel Aviv, Israel. Co Founder Maxillent LTD \\ ${ }^{3}$ Department of Oral Rehabilitation, The Maurice and Gabriela Goldschleger School of Dental Medicine, Tel Aviv University, Tel Aviv, Israel \\ ${ }^{4}$ Department of Oral and Maxillofacial Surgery and Periodontology, School of Dentistry of Ribeirão Preto, University of São Paulo, São Paulo, Brazil \\ ${ }^{5}$ Department of Oral and Maxillofacial Surgery, The Maurice and Gabriela Goldschleger School of Dental Medicine, Tel Aviv University, Tel Aviv, Israel \\ ${ }^{6}$ Department of Oral and Maxillofacial Surgery, Rabin Medical Center, Petah Tiqwa, Israel
}

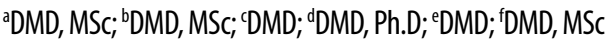

ABSTRACT

DOI: https://doi.org/10.25241/stomaeduj.2020.7(1).art.5

Introduction: Description of the immediate/early (up to one week) cone beam tomographic findings following maxillary sinus augmentation using a minimally invasive implant device.

Methodology: Aself-tapping endosseous dental implant containing an internal channel that allows the introduction of liquids through the implant body and into the maxillary sinus was used for sinus augmentation. A periapical radiography was performed at the end of the procedure. For those cases where the periapical radiograph could not demonstrate a clear postoperative result, a cone beam computerized tomography $(C B C T)$ was performed at the end of the procedure. When a CBCT device was not available an early $C B C T$ was performed within 1 week. Twenty immediate/early postoperative CBCT's were retrospectively evaluated for descriptive purposes.

Results: 25 immediate postoperative CBCT's were reviewed. The following radiological phenomena were noted and described - the postoperative appearance of the Schneiderian membrane; grafting material; new generated bone volume.

Conclusion: Dental CBCT should be the gold standard for immediate/early

OPEN ACCESS This is an Open Access article
under the CC BY-NC 4.0 license.
Peer-Reviewed Article
Citation: Chaushu L, Better H, Nissan J, Xavier SP,
Lorean A, Chaushu G. Immediate / early radiological
findings following transcrestal sinus augmentation
using a minimally invasive implant device. Stoma Edu J.
2020;7(1):35-41.
Received: November 15, 2019
Revised: January 09, 2020
Accepted: January 23, 2020
Published: January 28, 2020
Corresponding author:
Dr. Liat Chaushu, DMD, MSc
Department of Periodontology and Implant Dentistry,
The Maurice and Gabriela Goldschleger School of Dental
Medicine, Tel Aviv University, Tel Aviv, Israel.
Fax: $+972-86219999$, Tel: $+972-507821832$
e-mail: liat.natanel@gmail.com
Copyright: $\odot 2020$ the Editorial Council
for the Stomatology Edu Journal.
postoperative imaging, following transcrestal sinus augmentation using a minimally invasive implant device, to document post grafting conditions and allow early intervention in failures.

\section{KEYWORDS}

Dental; Oral Surgical Procedures; Preprosthetic; Radiography;

Sinus Floor Augmentation.

\section{INTRODUCTION}

Augmentation of the maxillary sinus floor followed by simultaneous or delayed placement of dental implants is a well-established technique for implantsupported rehabilitation of the partially or completely edentulous patient [1-15]. Few studies documented a patient's perception of recovery after sinus-floor augmentation [16]. The average patient should expect recovery within 5 days. As a result, patients may refuse the procedure due to fear, morbidity or other considerations. Several surgical techniques for sinus floor augmentation were described. The classical lateral window approach was described by Tatum in 1986 [17]. This surgical approach allows the clinician complete direct view of the sinus and enables sinus floor augmentation to the full extent necessary. However, it involves a significant amount of trauma to the patient [16]. The crestal approach was described by Summers in 1994 [18]. This surgical procedure minimizes much of the postoperative morbidity, however, it limits the surgeons' direct vision and is limited in its ability to augment the entire sinus floor.

The hydraulic sinus membrane elevation was first described by Chen and Cha in 2005 [19]. This is a variant of the Summers' technique. The fluid pressure from the drilling instrument is used to gently raise the sinus membrane from the sinus floor.

The present study focuses on a new procedure and a dedicated dental implant (iRaise sinus lift System by Herzliya, Tel Aviv, Israel) using the crestal approach $[4,5]$. This technique combines advantages of both 


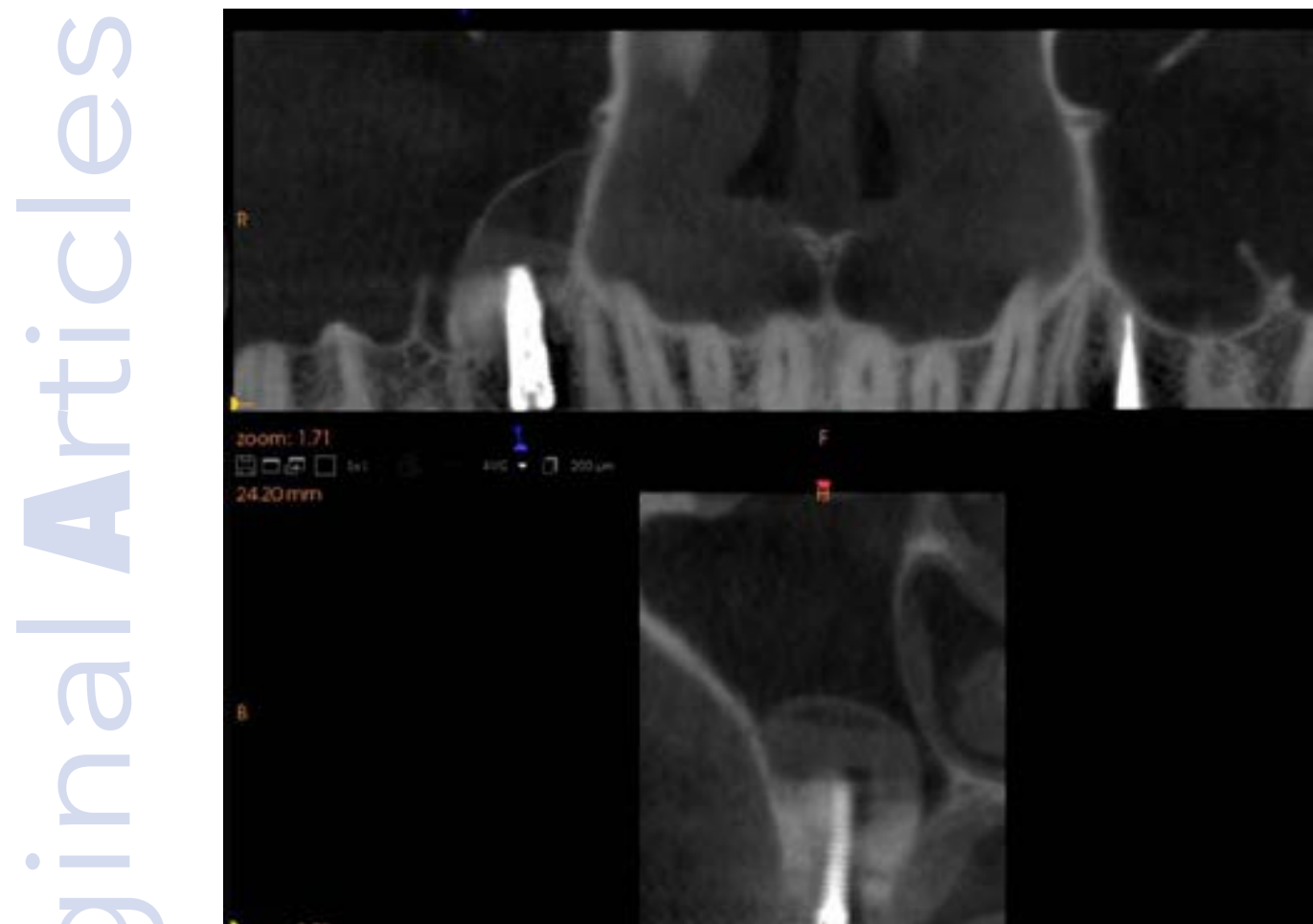

IFigure 1. Immediate postoperative view of a single implant.

the Tatum and Summers approaches, enabling sinus floor augmentation to the full extent necessary with minimum postoperative morbidity. Cone beam computed tomography (CBCT) provides a highly sophisticated format to precisely define the jaw structure and locate critical anatomic structures [20], and CBCT has been used in diagnosis, implant treatment [21], and evaluation of the changes after the sinus augmentation $[6,9,12,14,21-23]$. In the present study, the immediate and early (up to one week) tomographic findings following maxillary sinus augmentation using a minimally invasive implant device will be described.

\section{MATERIALS AND METHODS}

The dental implant used in this trial was a self-tapping endosseous dental implant $[4,5]$. It contains an internal channel that allows the introduction of liquids through the implant body and into the maxillary sinus. The device was approved for clinical testing by the ethical committees of the Israeli Ministry of Health following extensive preclinical and bench testing. The device also has a Conformité Européenne (CE) approval Health Canada and is allowed for distribution in Europe, Canada and Israel. The study was approved by the ethical committee of the Tel Aviv University.

\subsection{Surgical procedure}

Prophylactic antibiotics were administered $1 \mathrm{~g}$ of amoxicillin, 1 hour before the procedure). The patient performed a one-minute mouth wash with a chlorhexidine gluconate $0.2 \%$ solution. Surgery commenced with local anesthesia and a crestal incision, without vertical extensions, along the maxillary ridge.
Relatively small full thickness mucoperiosteal flaps were reflected. The osteotomy site was marked with a small round bur. An osteotomy was started at the implantation site with a $3.2-\mathrm{mm}$ twist drill to a depth of $3 \mathrm{~mm}$. The second drill is a flat tip drill up to 1 to $2 \mathrm{~mm}$ below the Schneiderian membrane, as measured by the preoperative radiograph. In some cases the operator used drills stoppers in order to accurately drill to the planed point under the sinus floor, in other cases the operator used a free hand drill with depth marking only. A periapical radiograph with a depth guide was performed in order to verify the drilling angulation and depth. The osteotomy site was widened to the desired diameter with the full drilling sequence for either a 4.2 or $5.0 \mathrm{~mm}$-diameter implant. The sinus floor was opened with a drill with an active diamond tip designed to atraumatically penetrate the sinus floor under the Schneiderian membrane with out damaging the membrane. The length of the implant (ranging from 13 to $16 \mathrm{~mm}$ ) was selected based on the residual bone height: a 13-mm length implant was used for bone heights of up to $5 \mathrm{~mm}$, a $14.5-\mathrm{mm}$ length implant was used for bone heights of up to $6.5 \mathrm{~mm}$, and a $16-\mathrm{mm}$ length implant was used for bone heights of up to $8 \mathrm{~mm}$. The implant was first inserted into the osteotomy until it reached the end of the prepared osteotomy. The implant was then slowly advanced until the sinus floor was penetrated (approximately $1 \mathrm{~mm}$ ). A periapical radiograph was performed in some cases in order to determine whether the implant penetrated the sinus floor. A saline syringe $(0.9 \%$ sodium chloride sterile saline solution) was connected to the implant via the tubing port. Saline solution was gently injected through the implant and into the sinus. Slight bleeding was 


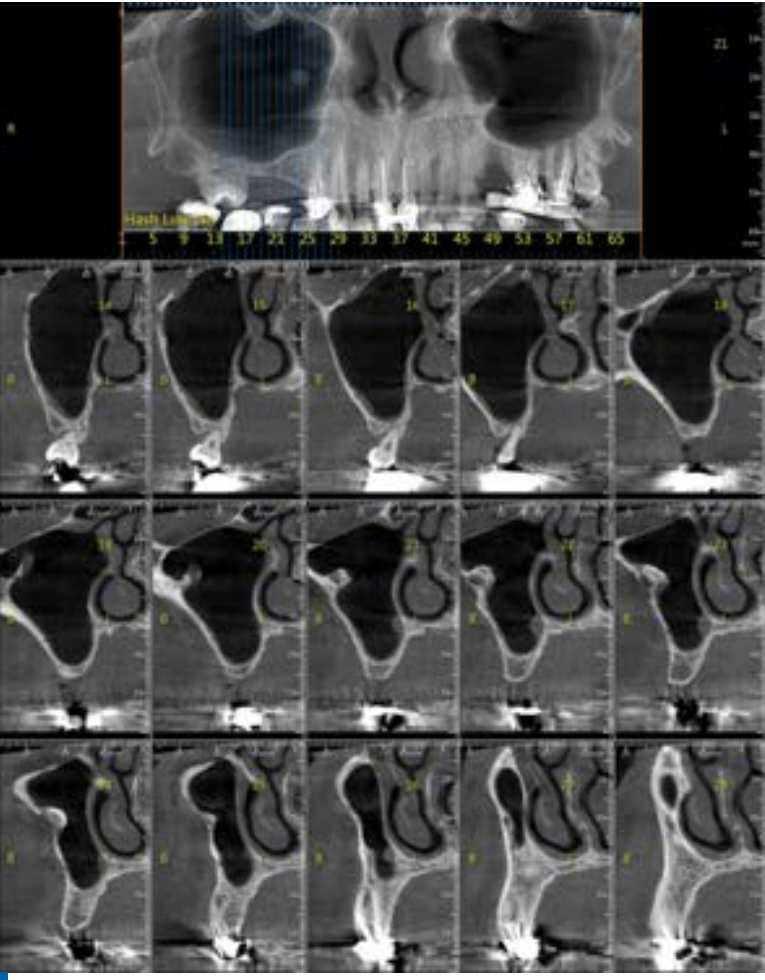

Figure 2a. Preoperative CT demonstrating slight thickening of the Schneiderian membrane.

noted in the retracted saline solution. This phenomenon served as a further indication that the implant tip penetrated the cortex. Blood was observed in the tubing upon stopping the injection or slightly draining fluid. Blood originated from the severed blood vessels connecting the Schneiderian membrane to the sinus bony walls. Typically, 2 to $3 \mathrm{~cm}^{3}$ of saline were required, depending on the size of the sinus, the number of implants, and the required elevation. The saline solution was retracted back into the syringe and the saline syringe was disconnected from the tubing port. A flowable bone graft filled syringe was then connected to the tubing port. The desired volume of bone graft material was then slowly injected through the implant into the sinus. The amount of bone graft ranged from 1 to $3 \mathrm{~cm}^{3}$, average $2.1 \mathrm{~cm}^{3}$. The bone graft syringe was subsequently disconnected from the tubing port and then the applicator and tubing together were disconnected from the implant. The implant was then fully inserted through the osteotomy into the bone graft until the coronal aspect of the implant was aligned with the maxillary alveolar crest. The gingival flaps were then sutured. A periapical radiography was performed at the end of the procedure. For those cases where the periapical radiograph could not demonstrate a clear postoperative result, a CBCT was performed at the end of the procedure. When a $C B C T$ device was not available an early CBCT was performed within 1 week. Twenty immediate/early postoperative CBCT's were retrospectively evaluated for descriptive purposes.

Following the procedure the patients were instructed to perform mouth rinsing for 1 minute with $0.2 \%$ chlorhexidine solution, twice a day, for 10 days. Post-

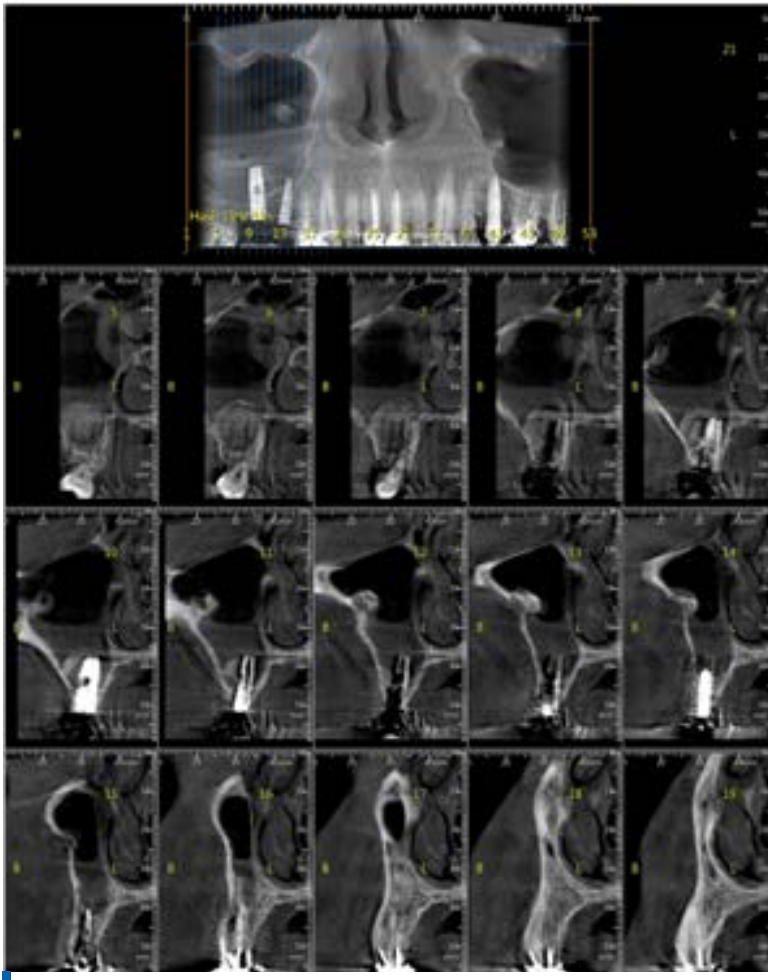

Figure $\mathbf{2 b}$. Postperative CT demonstrating moderate thickening of the Schneiderian membrane.

operative analgesia was used as needed. Nose drops (topical decongestants such as oxymetazoline) were used in the relevant nostril twice a day for a week. Antibiotics were prescribed at the clinician's discretion (as usually given in bone grafting procedures): $3 \times 500 \mathrm{mg}$ amoxicillin for 7 days.

\section{RESULTS}

25 immediate postoperative CBCT's were reviewed. The following radiological phenomena were noted:

O Schneiderian membrane (Fig. 1)

A clear membrane was noted in all CBCT scans allowing a distinction between the grafted area and the rest of the sinus. The Scneiderian membrane appeared as a narrow hyperdense line.

OLack of membrane perforation (Fig. 1)

The thin line of the Schneiderian membrane is seen encircling the entire new content (air, water, bone) without any perforated area. None of the included materials is seen outside the membrane, within the sinus.

Postoperative swelling of the sinus membrane (Fig. 2)

All cases demonstrated a slight postoperative swelling of the sinus membrane without any signs of inflammation.

OPalatal coverage of the membrane (Fig. 1)

The membrane is not necessarily elevated for all the bony walls. The elevation is probably proportional to the amount of residual alveolar ridge, pressure from the injectable fluids and connection between the membrane and the bone.

OFlush and compact adaptation of the grafting material (Fig. 1) 


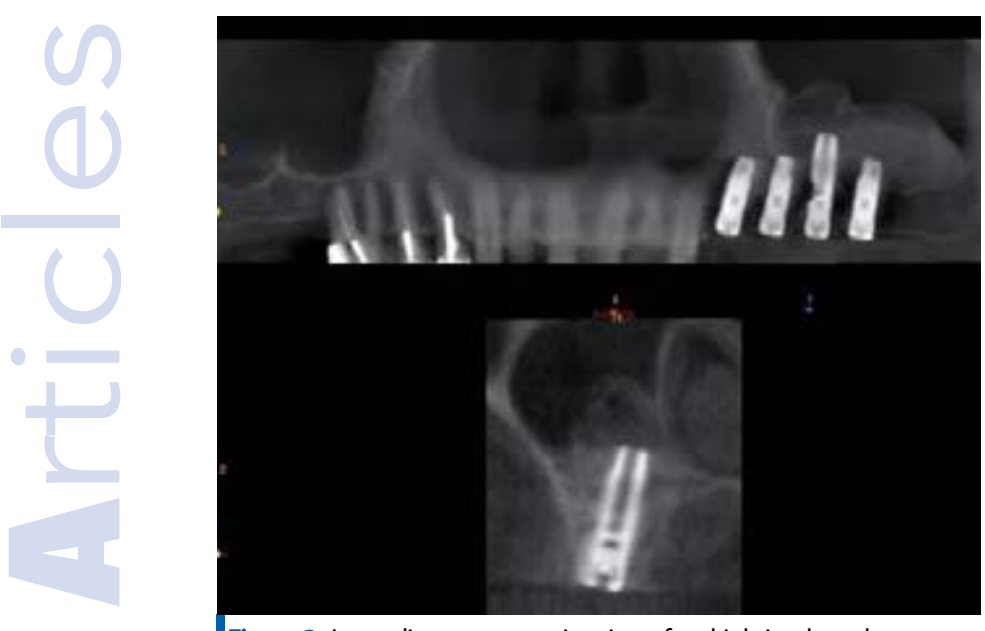

Figure 3. Immediate postoperative view of multiple implant placement.

Cases without additional implant placement demonstrated flush and compact adaptation of the bone graft to the sinus floor. When additional implants were inserted irregular combinations of the hyperdense and hypodense areas were noted as a result fluid insertion and graft extrusion during the osteotomy preparation. (Figs. 3,4)

OCreation of 4 layers according to molecular weight (Fig. 1)

Some immediate postoperative CBCT's demonstrated 4 layers according to molecular weight. The most crestal is the original residual alveolar ridge. The second is the injected bone graft. The third as water / blood from the severed Schneiderian membrane vessels and the most apical layer was air.

The layers may be arranged in either a homogenous pattern or in a completely non-homogenous one. Another factor is probably the additional drilling into the sinus floor while adding implant, which can stir the bone graft and fluid inside the space created under the Schneiderian membrane. (it is possible that it may take time for the layers to become homogeneous as when you mix oil and water)

O Elevation direction (Figs. 1-4)

There is no absolute control of the elevation amount and direction. The membrane may be elevated either superiorly, distally, mesially, palatally or any combination of the above.

\section{Membrane shape}

In some cases the membrane obtains a ball/balloon like appearance (Fig. 1) whereas in others it may obtain a completely irregular plastic shape (Figs. 3,4).

\section{DISCUSSION}

Injectable bone substitutes are a combination of xenografts, allografts, alloplasts and liquid components. Injectable alloplast proved to be very useful when applied via a minimally invasive dental implant device. The fluid organic components serve as a binder for the anorganic bone substitute particles. The organic materials prevent wash out of the particles from the grafted site.[24] In order to allow optimal flow characteristics injectable grafts are further

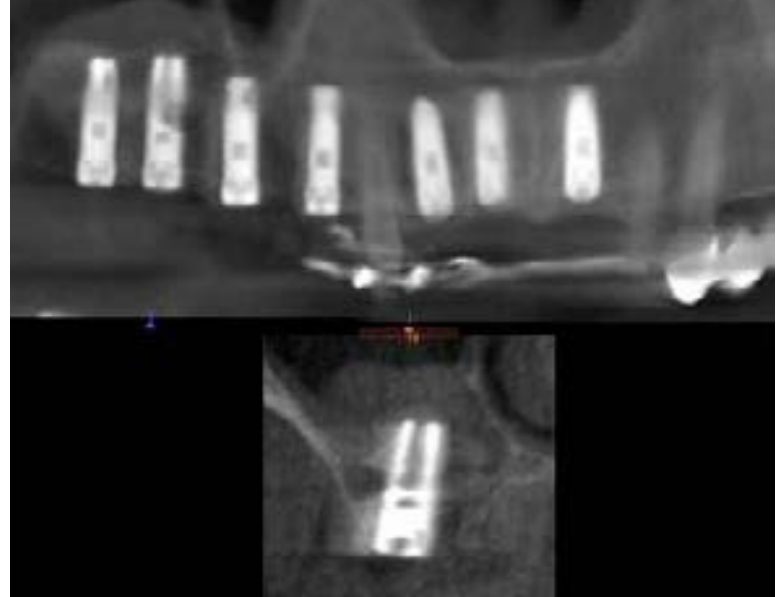

Figure 4. Immediate postoperative view of multiple implant placement.

diluted. As a result the injected grafting material can easily glide between the Schneiderian membrane and the sinus floor without causing pain or injury [25]. For clinical purposes prolonged storage of such ready-to-use injectable bone substitute materials is mandatory. A neutral $\mathrm{pH}$ is the best solution for this requirement $[25,26]$. Their fluidity and adaptability to the host tissue is another mandatory requirement. Thus, it can be speculated that the hyper dense view of the Schneiderian membrane is a result of the increased concentration of the bone substitute macromolecules adapting fast to the membrane as a result of their fluidity. Sinus membrane integrity is essential for the success of the transcrestal sinus augmentation. Membrane perforations occur in $0-21.4 \%$ of the transcrestal procedures [27-28]. Ruling out in such cases is mandatory since there is very limited possibility to repair such tears jeopardizing the entire hydraulic elevation procedure. A clinical option is doing a valsalva maneuver and observing the osteotomy site that no air bubbles are coming out during the maneuver. A dental CBCT provides conclusive post op information about such a perforation either by following the white hyperdense membrane line or making sure there is no dislodged graft material in the sinus beyond the Schneiderian membrane. Injectable bone substitutes affect sedimentation the creation of precipitation layers according to the law of gravity [24-26]. This is the explanation for the 4 layers noted on CBCT - residual alveolar ridge, injectable bone graft, water and blood, air. This arrangement allows us to assure the intimate contact of the graft to the native bone permitting good graft consolidation. On the other hand, this finding should also raise the question of whether studies concerning bone resorption along time represent true resorption or are merely an expression of water and air content disappearance. Such questions should be taken in consideration in future studies allowing us to better understand the resorptive processes following sinus augmentation [29-31]. The graft consolidation gradient is a term describing new bone formation on the one hand vs. bone substitute disappearance [33]. Since we are talking about a gradient, both phenom- 
ena are evaluated as a function of the distance from either the host bone or the implant. Behavior close to the host bone will teach us concerning the new volume consolidation while close to the implant - concerning osseointegration. Injectable grafts are fast resorbing materials [32]. It is known that such materials disappear relatively fast from both sites allowing new bone formation. Therefore, we should dedicate all our efforts to exposing the palatal site and elevating the sinus membrane. Otherwise, the palatal part of the bone will not participate in the formation of new bone. As a result, lower new bone quantity and quality will be formed, lowering the biomechanical abilities of the inserted new implants to withstand occlusal forces [33]. Neverthless, there are reports in the literature that just tenting of the Schneiderian membrane without bone graft may be sufficient in order to create new bone under the elevated and separated from the sinus floor Schneiderian membrane. Probably blood clot is transformed into bone in that situation [34]. Due to Pascal's law it is difficult to obtain complete control of the membrane elevation. Water will search the lowest resistant point to detach the membrane from the sinus floor $[35,36]$. Therefore, if we have any doubt it is better to use more fluid for elevation, to allow bony exposure and better fluidity of the bone grafting material. While membrane thickness in humans ranges from 24$350 \mu \mathrm{m}$ with a mean of $40 \mu \mathrm{m}$, in animals it ranges 68-318 $\mu \mathrm{m}$ [37]. Animal model studies led to the wrong conclusion that the Schneiderian membrane is elastic and responds to pressure like a balloon. The present study clearly shows that the "balloon" behavior is rather the exception than the rule. The more frequently seen behavior is plastic, obtaining

\section{REFERENCES}

1. Xavier SP, Dias RR, Sehn FP, et al. Maxillary sinus grafting with autograft vs. fresh frozen allograft: a split-mouth histomorphometric study. Clin Oral Implants Res. 2015;26(9):10801085.

[Full text links] [CrossRef] [PubMed] Google Scholar Scopus

2. Xavier SP, Silva ER, Kahn A, et al. Maxillary sinus grafting with autograft versus fresh-frozen allograft: a split-mouth evaluation of bone volume dynamics. Int J Oral Maxillofac Implants. 2015;30(5):1137-1142.

[Full text links] [CrossRef] [PubMed] Google Scholar Scopus 3. Sehn FP, Dias RR, de Santana Santos T, et al. Fresh-frozen allografts combined with bovine bone mineral enhance bone formation in sinus augmentation. J Biomater Appl. 2015:29(7):1003-1013. [Full text links] [CrossRef] [PubMed] Google Scholar Scopus 4. Better $H$, Slavescu D, Barbu $H$, et al. Patients perceptions of recovery after maxillary sinus augmentation with a minimally invasive implant device. Quintessence Int. 2014;45(9):779-787. doi:10.3290/j.qi.a32510

[Full text links] [PubMed] Google Scholar Scopus

5. Better $\mathrm{H}$, Slavescu D, Barbu $\mathrm{H}$, et al. Minimally invasive sinus lift implant device: a multicenter safety and efficacy trial preliminary results. Clin Implant Dent Relat Res. 2014;16(4):520-526.

[Full text links] [CrossRef] [PubMed] Google Scholar Scopus

6. Mardinger O, Chaushu G, Sigalov S, et al. Factors affecting changes in sinus graft height between and above the placed implants. Oral Surg Oral Med Oral Pathol Oral Radiol Endod. 2011;111(1):e6-e11.

[Full text links] [CrossRef] [PubMed] Google Scholar Scopus

7. Mardinger $\mathrm{O}$, Moses $\mathrm{O}$, Chaushu $\mathrm{G}$, et al. Challenges associated with reentry maxillary sinus augmentation. Oral Surg Oral Med Oral Pathol Oral Radiol Endod. 2010;110(3):287-291. any possible shape. This is one more reason why there are fewer chances for tearing the membrane during elevation with the hydraulic technique vs. the balloon technique.

Hydraulic sinus elevation is not a new idea. Sinus endoscopy maybe an additional (albeit invasive) technique to assure lack of sinus membrane perforation. $\mathrm{CBCT}$ is probably more precise but involves $\mathrm{X}$-ray exposure. An additional disadvantage is the inability to detect small rupture immediately after surgery. A long-time comparative randomized study can give us more precise information.

\section{CONCLUSION}

Dental CBCT is considered the gold standard for sinus diagnosis and surgical planning of sinus augmentation. The present study suggests that CBCT should also be the gold standard for immediate or early postoperative imaging, following transcrestal sinus augmentation, using minimally invasive implant device, to document post grafting conditions and allow early intervention in failures.

\section{CONFLICT OF INTEREST}

The authors declare no conflict of interest.

\section{AUTHOR CONTRIBUTIONS}

$\mathrm{CL}$ : study design, data collection, writing the manuscript; $\mathrm{BH}$ : data collection; NJ: approval of the final version; XSP: approval of thefinal version; LA: data collection; CG: study design, data collection, writing the manuscript.
[Full text links] [CrossRef] [PubMed] Google Scholar

8. Chaushu G, Vered M, Mardinger O, Nissan J. Histomorphometric analysis after maxillary sinus floor augmentation using cancellous bone-block allograft. J Periodontol. 2010;81(8):1147-1152. [CrossRef] [PubMed] Google Scholar Scopus

9. Manor Y, Mardinger O, Bietlitum I, et al. Late signs and symptoms of maxillary sinusitis after sinus augmentation. Oral Surg Oral Med Oral Pathol Oral Radiol Endod. 2010;110(1):e1-e4.

[CrossRef] [PubMed] Google Scholar Scopus

10. Chaushu G, Mardinger O, Calderon S, et al. The use of cancellous block allograft for sinus floor augmentation with simultaneous implant placement in the posterior atrophic maxilla. J Periodontol. 2009;80(3):422-428.

[CrossRef] [PubMed] Google Scholar Scopus

11. Mardinger $O$, Nissan J, Chaushu G. Sinus floor augmentation with simultaneous implant placement in the severely atrophic maxilla: technical problems and complications. J Periodontol. 2007;78(10):1872-1877.

[CrossRef] [PubMed] Google Scholar Scopus

12. Shlomi B, Horowitz I, Kahn A, et al. The effect of sinus membrane perforation and repair with Lambone on the outcome of maxillary sinus floor augmentation: a radiographic assessment. Int J Oral Maxillofac Implants. 2004;19(4):559-562. [PubMed] Google Scholar Scopus

13. Mazor Z Peleg M, Garg AK, Chaushu G. The use of hydroxyapatite bone cement for sinus floor augmentation with simultaneous implant placement in the atrophic maxilla. A report of 10 cases. J Periodontol. 2000;71(7):1187-1194. [CrossRef] [PubMed] Google Scholar Scopus

14. Peleg M, Chaushu G, Mazor Z, et al. Radiological findings of the post-sinus lift maxillary sinus: a computerized tomography 
follow-up. J Periodontol. 1999;70(12):1564-1573.

[CrossRef] [PubMed] Google Scholar Scopus

15. Peleg M, Mazor Z, Chaushu G, Garg AK. Sinus floor augmentation with simultaneous implant placement in the severely atrophic maxilla. J Periodontol. 1998;69(12):1397-1403.

[CrossRef] [PubMed] Google Scholar Scopus

16. Mardinger $\mathrm{O}$, Poliakov $\mathrm{H}$, Beitlitum I, et al. The patient's perception of recovery after maxillary sinus augmentation: a prospective study. J Periodontol. 2009;80(4):572-576.

[CrossRef] [PubMed] Google Scholar Scopus

17. Tatum H Jr. Maxillary and sinus implant reconstructions. Dent Clin North Am. 1986;30(2):207-229.

Google Scholar Scopus

18. Summers RB. A new concept in maxillary implant surgery: the osteotome technique. Compendium. 1994;15(2):152-162.

[PubMed] Google Scholar Scopus

19. Chen L, Cha J. An 8-year retrospective study: 1,100 patients receiving 1,557 implants using the minimally invasive hydraulic sinus condensing technique. J Periodontol. 2005;76(3):482-491.

[CrossRef] [PubMed] Google Scholar Scopus

20. Garg AK, Vicari A. Radiographic modalities for diagnosis and treatment planning in implant dentistry. Implant Soc. 1995;5(5):7-11. [PubMed] Google Scholar Scopus

21. Wanschitz F, Figl M, Wagner A, Ewers R. Measurement of volume changes after sinus floor augmentation with a phycogenic hydroxyapatite. Int J Oral Maxillofac Implants. 2006;21(3):433-438. [PubMed] Google Scholar Scopus

22. Kirmeier R, Payer M, Wehrschuetz M, et al. Evaluation of threedimensional changes after sinus floor augmentation with different grafting materials. Clin Oral Implants Res. 2008;19(4):366-372.

[Full text links] [CrossRef] [PubMed] Google Scholar Scopus

23. Szabó G, Suba Z, Hrabák K, et al. Autogenous bone versus betatricalcium phosphate graft alone for bilateral sinus elevations (2- and 3-dimensional computed tomographic, histologic, and histomorphometric evaluations): preliminary results. Int J Oral Maxillofac Implants. 2001;16(5):681-692.

[CrossRef] [PubMed] Google Scholar

24. Uda H, Sugawara $Y$, Nakasu M. Experimental studies on hydroxyapatite powder-carboxymethyl chitin composite: injectable material for bone augmentation. J Plast Reconstr Aesthet Surg. 2006;59(2):188-196.

[Full text links] [CrossRef] [PubMed] Google Scholar Scopus

25. Gérentes P, Vachoud L, Doury J, Domard A. Study of a chitin-based gel as injectable material in periodontal surgery. Biomaterials. 2002;23(5):1295-1302.

[Full text links] [CrossRef] [PubMed] Google Scholar Scopus

26. Weiss P, Gauthier O, Bouler JM, et al. Injectable bone substitute using a hydrophilic polymer. Bone. 1999;25(2 Suppl):67S-70S.

[Full text links] [CrossRef] [PubMed] Google Scholar Scopus

27. Kim DY, Itoh Y, Kang TH. Evaluation of the effectiveness of a wate

lift system in the sinus membrane-lifting operation as a sinus surgical instrument. Clin Implant Dent Relat Res. 2012;14(4):585-594.
[Full text links] [CrossRef] [PubMed] Google Scholar Scopus

28. Tan WC, Lang NP, Zwahlen M, Pjetursson BE. A systematic review of the success of sinus floor elevation and survival of implants inserted in combination with sinus floor elevation. Part II: transalveolar technique. J Clin Periodontol. 2008;35(8

[Full text links] [CrossRef] [PubMed] Google Scholar Scopus

29. Xavier SP, Silva ER, Kahn A, et al. Maxillary sinus grafting with autograft versus fresh-frozen allograft: a split-mouth evaluation of bone volume dynamics. Int J Oral Maxillofac Implants. 2015;30(5):1137-1142.

[Full text links] [CrossRef] [PubMed] Google Scholar Scopus

30. Sbordone C, Toti P, Guidetti F, et al. Volumetric changes after sinus augmentation using blocks of autogenous iliac bone or freeze-dried allogeneic bone. A non-randomized study. J Craniomaxillofac Surg. 2014;42(2):113-118.

[Full text links] [CrossRef] [PubMed] Google Scholar Scopus

31. Berberi A, Bouserhal $L$, Nader $N$, et al. Evaluation of threedimensional volumetric changes after sinus floor augmentation with mineralized cortical bone allograft. J Maxillofac Oral Surg. 2015;14(3):624-629.

[Full text links] [CrossRef] [PubMed] Google Scholar Scopus

32. Busenlechner D, Huber CD, Vasak C, et al. Sinus augmentation analysis revised: the gradient of graft consolidation. Clin Oral Implants Res. 2009;20(10):1078-1083.

[Full text links] [CrossRef] [PubMed] Google Scholar Scopus 33. Tepper G, Haas R, Zechner W, et al. Three-dimensional finite element analysis of implant stability in the atrophic posterio maxilla: a mathematical study of the sinus floor augmentation. Clin Oral Implants Res. 2002;13(6):657-665.

[Full text links] [CrossRef] [PubMed] Google Scholar Scopus

34. Jungner M, Cricchio G, Salata LA, et al. On the Early Mechanisms of Bone Formation after Maxillary Sinus Membrane Elevation: An Experimental Histological and Immunohistochemical Study. Clin Implant Dent Relat Res. 2015;17(6):1092-1102.

[Full text links] [CrossRef] [PubMed] Google Scholar Scopus

35. Pommer B, Watzek G. Gel-pressure technique for flapless transcrestal maxillary sinus floor elevation: a preliminary cadaveric study of a new surgical technique. Int J Oral Maxillofac Implants. 2009:24(5):817-822.

[PubMed] Google Scholar Scopus

36. Pommer $B$, Unger $E$, Sütö $D$, et al. Mechanical properties of the Schneiderian membrane in vitro. Clin Oral Implants Res. 2009;20(6):633-637.

[Full text links] [CrossRef] [PubMed] Google Scholar Scopus

37. Watzek G, Pommer B, Strbac GD. Status quo analysis. In: Watzek $\mathrm{G}$, editor. The precrestal sinus lift from illusion to reality. London, UK: Quintessence Publishing Co. Ltd; 2012.

Google Scholar

\section{Liat CHAUSHU \\ DMD, MSC Department of Periodontology and Implant Dentistry The Maurice and Gabriela Goldschleger School of Dental Medicine Tel Aviv-University Tel Aviv, Israel

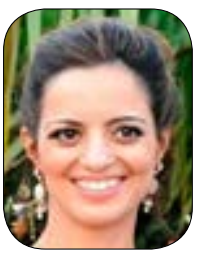

Graduated magna cum laude at Maurice and Gabriela Goldschleger school of Dental Medicine, Tel Aviv University, Tel Aviv, Israel. Completed her MSc. Degree at Sackler Faculty of Medicine, Tel Aviv University, Tel Aviv, Israel. Graduate of the periodontology program and member of the department of periodontology and implant dentistry, the Maurice and Gabriela Goldschleger School of Dental Medicine, Tel Aviv University, Tel Aviv, Israel. Graduate of the European federation of periodontology. A member of the Israeli society of Periodondology and Osseointegration. A member of the European Federation of Periodontology. A member of Israeli Dental Association. Lectures nationally and internationally. Published over 20 manuscripts in peer-reviewed journals. Founder of an Israeli start-up company, Implant B, with a unique patent for the treatment of peri-implant disease. 


\section{Ouestions}

\section{How many layers were noted postoperatively?}

ㅁ. 1;

ab. 2;

ac. 3;

ad. 4.

\section{Perforations can be noted easily in the postop CBCT:}

口a. Yes;

ab. No;

ac. It is not possible to see perforations on CBCT;

$\square \mathrm{d}$. Resorbable collagen membranes should always be placed on the Schneiderian membrane.

3. The Schneiderian membrane always appears as a balloon following sinus elevation:

口a. Yes;

ab. No;

ac. It is not possible to see the Schneiderian membrane on CBCT;

$\square$ d. Only if you use a balloon for sinus elevation.

\section{The 4 layers are best noted in cases of :}

口a. Single implant;

ab. Multiple implants;

ac. Not relevant;

ad. Similar.

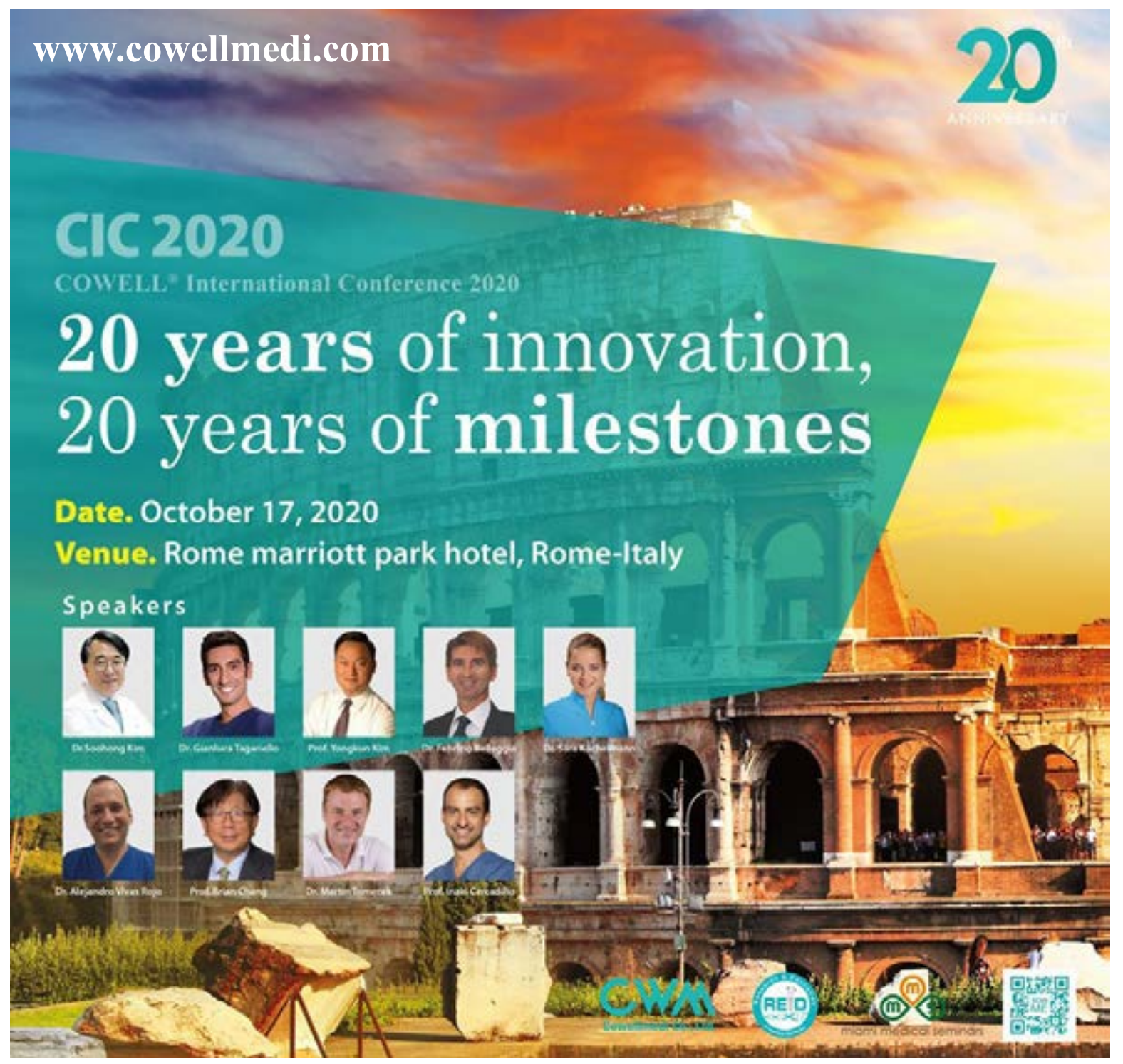

